\title{
Aegean Sea-Challenges and Dilemmas in Management and Planning for Local Development in Fragmented Insular Regions
}

\author{
Yiota Theodora \\ Department of Urban and Regional Planning, School of Architecture, National Technical University of \\ Athens (N.T.U.A.), Patission 42, 10682 Athens, Greece; ptheodora@arch.ntua.gr
}

Received: 14 April 2019; Accepted: 22 June 2019; Published: 28 June 2019

\begin{abstract}
In an age of network organization and the digital revolution, under conditions of intense international competition alongside a multifaceted economic downturn, a new form of economy is developing, shaped by the learning society and knowledge-based economy. Under exceptionally difficult conditions where, despite all intentions, economic growth remains the main concern, often without terms or criteria, and even at environmental, territorial and socio-economic cost, the issue: Development for whom, where and on what terms remains "open". In Greece decades-long unquestioning adoption of developmental models in conjunction with a methodically organized diminishment of the territorial dimension has undermined acquis which had been promoted for years as a prerequisite for life, re-introducing to the discussion the issue of how to plan the various levels and categories of territory, protecting the history and physiognomy of place, ensuring local development in terms of social justice and sustainability in an intensely globalised environment. An answer is sought regarding how best to manage human resources and cultural heritage on the basis of territorial/sectoral and social collaborative networks that are supralocal and transnational focusing on the model of "endogenous development". Based on research experience regarding the Mediterranean and the Aegean, the article aims to underline the absence of a comprehensive island policy in Greece and highlight crucial issues that need to be resolved at the level of developmental and planning choices in order to eliminate instances of downgrading/abandonment of vulnerable remote and insular border regions. The proposals which are formulated are intended to contribute to the debate about a more equal development for islands and insular areas at a critical juncture for Greece.
\end{abstract}

Keywords: insular planning; coastal planning; maritime spatial planning; urban development; regional development; participatory planning; spatial/sectoral/social networks; local communities; cultural heritage

\section{Defining the Scope of the Discussion}

Achievement of local and regional developmentobjectives in a highly globalised environment continues to concern, worry and also divide the international scientific community and the decision-makers at the various spatial levels. The manifold consequences of the still in progress, multifaceted economic downturn on a variety of spatial levels demands robust planning practices and designates flexible innovative mechanisms in order for new developmental action plans to be formulated that are capable of responding to contemporary global and local challenges. It is not simply random that research interests over the past few years have focused on seeking strategies for productive redeployment in order the transition to the new age economy to be accomplished [1,2].

Recognising that development is not a spatially-neutral process, dealing with the fallout of sector-based structure of production and employment cannot and should not be attempted without 
regard to the spatial context and the local communities. This holds true in the current era, where human resources and place identity become increasingly important in the management/regulation of the spatial context in all its units/categories, under conditions of: (i) Intense network organisation of the main means of production, services, infrastructure; (ii) intensifying international competition; (iii) digital revolution; (iv) a dominant "new" form of economy, whose main pillars are the learning society and the knowledge-based economy [3-7].

Indubitably, the dramatic political, social and economic shifts particularly over the past thirty years have marked significant redevelopments in the structure and organization of both the urban and rural space and in the concepts of their development and their planning practices, particularly in instances of vulnerable areas, i.e., spatial/functional modules with significant problems of decline or abandonment which, however, display particular dynamics and prospects for a series of reasons (e.g., geopolitical position and role, climate, natural/cultural available resources). As such, they can be considered coastal, insular, mountain and border/frontier areas, where pressures and conflicting interests formulate an explosive environment. New data/trends demand that criteria be designated to formulate action plans in response to contemporary challenges for local-regional development. We find ourselves at the start of a new age for the role of spatial planning in developmental policy, where there is an intense debate on defining new models for development and on the orientation of spatial policies so that urban and rural areas can function as nuclei of development, ensuring both authenticity and resilience of these places. At the same time there is an ever-expanding interest in the management of maritime space, which raises many questions about planning and the levels of correlation with coastal and insular areas. Values such as social justice and equality; quality of life; protection of the natural, cultural and architectural wealth; promotion of tradition and memory; and management of creativity are gaining exceptional concern in the event of a crisis, where the globalised economy and the modern forms of production, in conjunction with the intense geopolitical shifts and the manifold consequences of climate change, do not set in motion the same processes of urban-(trans-) regional reformation, nor do they have the same effect on regions and societies [8-11].

Under such conditions of spatial-functional reformation and, despite the research interest in the form, structure, features and dynamics of urban space in rural areas (mountain, coastal, insular), unfortunately the urban development policy at the EU and state level continues to be in an early phase, in contrast with the long tradition of exercising regional policy. Whatever measures exist to support cities, settlements and conurbations (double-centred, multi-centred) remain incorporated in other joint policies or are promoted in the framework of research programmes. A similar situation exists in developmental policies for special land categories such as coastal, insular, mountain, border/frontier spaces. This fact brings up issues of spatial management and regulation, particularly in areas where issues of intense, often unplanned, settlement expansion are encountered; where incompatible uses are taking place; where the local economy is based mainly on activities like tourism and recreation; and where non-rational use of natural/cultural resources is taking place. Dominance of such issues reinforces pressures on natural and manmade ecosystems, threatening the carrying capacity and the authenticity of areas and local communities $[4,9,12]$.

In this framework of multiplex processes, resulting from the new conditions prevailing in the international markets and the choice of the dominant development model within states at national scale, spatial transformations make up a complex situation of urban dynamics. New spatial forms of development are emerging, while the modus operandi of (central) urban areas is changing due to the different role they acquire. Countries have long ceased to be envisaged as closed autonomous systems, while cities seek collaboration by setting-up production and distribution networks going beyond the state level. The urban space acquires new forms and takes up new dimensions, where new hierarchies prevail through the organisation of spatial, thematic, quality networks in all territorial scales $[8,11,13-15]$. In such conditions of spatial reformation and urban alliances, there is evidence to be found that it is not only cities with the infrastructure to generate knowledge, innovation, know-how that contribute to the developmental process, but also cities that can appropriate such a process in 
order to improve production conditions and put their tradition and creativity to use [16]. At the same time, countryside settlements gain a new dynamic as a portion of a multifunctional space, which should not be treated exclusively based on agriculture. Rural regions constitute a particularly complex environment with significant diversity. They are, in other words, complex economic, physical, cultural sites that cannot and should not be dealt with on the basis of population size, agriculture and natural resources. They are areas which differ significantly amongst themselves, but also within themselves, so it is therefore necessary to also assess their individual qualities in each instance, in order to make use of their capacities to the greatest extent possible [10]. In the instance of nations like Greece, with a significant number of rural areas hosting settlements or networks of settlements with a unique history and identity, it is apparent that there is a need to re-examine the relationship between the city and the countryside, and redefine the role of cultural heritage, human resources and their skills in the developmental process. Already, the stance towards tackling issues which concern protecting historicity, conservation and development of historical cities and settlements and their seamless adaptation to modern life is being steadily reinforced. There is a similar interest for utilising the historic centres of cities as "dynamic pockets of memory and action". These trends are extremely critical in spatial planning/design, since they bring up issues of how to deal with them, while featuring the major transitions that can be brought about in the strategic choices of modern spatial policies [5,13,15,17-19].

In jointly evaluating contemporary concepts on spatial development-planning at a European level and the ever-expanding quest for immediate economic growth (often without any terms or criteria, and even at environmental, spatial and socio-economic cost), this article seeks to make a contribution to the discussion currently taking place by underlining the need to change the manner in which we consider the management of natural, cultural and human resources in Greece. An answer is sought regarding how best to manage human resources and cultural heritage on the basis of territorial/sectoral/social collaborative networks that are supralocal and transnational focusing on the model of "endogenous development". However, how can these networks contrive to function as people loci and not as homogenised impersonal "receptors" of hyper-concentrated activities and infrastructure? In order to achieve such a goal, priority must be given to satisfying the real needs of the population (i.e., needs as they are perceived by the users and not the administration) [2]. It is also important to ensure democratic planning $[20,21]$, which will allow active citizen participation, in order to avoid adopting top-down developmental models or planning practices and decision making irrespective of the identity of the locus and the demands and priorities of the population. In practice, unfortunately, such a goal usually (if not always) remains a matter of intent due to petty political interests, with the usual consequences for local societies, namely in complex and fragile areas, such as island, mountain, frontier, border space, where phenomena of insularity, seasonality, degradation and abandonment prevail.

More specifically, the article selects to focus its research interest on vulnerable segments of the insular space, i.e., on a category of space of a great importance for the development of coastal/island countries, like Greece. In other words, on territories where the agricultural economy continues to be dominant and these production activities that are directly linked or correlated are developing, while there also exists an increasing interest in the development of various forms of tourism and recreation. Focus is on places where one can often encounter noteworthy elements of nature and culture at sea, in the coastal zone and the interior, as well as a network of city ports of local or supralocal interests (as a part of a broader settlement grid) which is organised on islands of different dynamics and even under conditions of strong dominance of intra-and inter-municipal and regional inequities and the simultaneous inability to configure collaborations structures, not only at an island level, or between each other, or even with the continental segments of the country to which they belong or neighbouring countries [2,11,22].

Based on experience gained from researches regarding the management of the maritime space $[14,22]$ and human resources and cultural heritage $[5,15,23]$, as well as an ongoing research in the Aegean (Sections 2, 5 and 6), the article's objective is to underline the absence of a comprehensive island policy in Greece at the national level and focus its attention on issues that need to be 
resolved at the level of developmental and planning choices in order to eliminate instances of downgrading/deterioration/abandonment of vulnerable remote and insular border regions. The proposals which are formulated in the present stage intend to contribute to a debate about a more equal sustainable development for islands and insular areas at a critical juncture for Greece. They actually seek to function as a "starting point" for re-evaluating and redefining the way of dealing with spatial issues and taking advantage of local comparative advantages in order to trigger further study at a local/trans-regional level. At a spatial level, i.e., where consequences of developmental/planning choices can be evaluated with greater accuracy $[2,4,10,13,21,22]$ (Supplementary Materials).

\section{Determining the Methodological Approach}

Based on this rational and in an effort to contribute to the discussion regarding the need for a cohesive clearly expressed Greek island policy, the first subsection of the second chapter sets out the structure and rationale of the research approach, as well as the sources used (Section 2.1). The second subsection describes the main object, the aim and the reference areas of research carried out in the Aegean Sea and how it contributes to the subject matter approach (Section 2.2).

The Aegean Sea was not selected at random (Section 6). The Aegean is a locus with conflicting interests and claims with local consequences. A place where issues of crucial geopolitical importance coexist with incompatible activities and trans-national networks (shipping, commerce, tourism, energy, etc.), a concentration of natural/cultural wealth, as well as a pressure because of the strong migrant/refugee flows. At the same time the regions of the Aegean Sea display spatial discontinuity and heterogeneity (mainly in terms of geopolitical pull, expanse, identity, dynamics) that often render it difficult (or impossible) to adopt proven policies, tools and procedures. Therefore, the objective is to identify policies, which are linked to "endogenous development", tools for spatial networking, and procedures for democratic planning and incorporating new technologies in the planning process and the everyday life of inhabitants. This is verified at a local level, where it is demonstrated in practice that safeguarding networks, establishing democratic planning and using new technologies is not at all self-evident in areas where the local societies are unable to adapt to new conditions $[13,21,23]$. This is where issues which have already been addressed and have yielded measurable results elsewhere remain unanswered. We actually refer to a complex area faced with a multitude of spatial management and development issues. It thus becomes a challenging field for research and experimentation on all its spatial levels. Mainly, local and (inter)regional levels are of particular interest, because they clearly demonstrate that topics linked to spatial regulation and development concepts and practices, which are considered to be known or to have been answered, in Greek case remain "open". In fact, it is deemed that some of these issues should be part of its national insular policy, in order for the islands and insular areas to become an "opportunity" for the country rather than a "problem" (Sections 6 and 7).

\subsection{The Basic Levels of Research}

The proposed research methodology focuses on two parallel interrelated levels of research. Figure 1 illustrates the two levels (A) and (B) and the themes of reference, which formed the basis for the approach of the third level (C), aimed at designing a Greek insular policy. On level (C) there are proposals on the definition of the main proposed policy components to safeguard a fairer and more sustainable development of Greek insular space. The "key" fields, which form the current core of reference, are brightly coloured (Figure 1).

The first research level (A) refers to new conditions and trends, involved in safeguarding local and regional development in the context of a global planning (Section 3), the main components of which are: (i) Dominance of networking; (i) democratic planning and new actors; (iii) technology revolution; (iv) promotion of human resources and cultural heritage as development factors (Section 4). This is the sort of planning that promotes the organization of "smart creative places" as a means of restarting local communities $[1,8,24]$. In practice, however, it seeks immediate economic growth, often neglecting potential repercussions on a local level. This is a contradiction that influences the structure of spatial 
policies, as it determines the focus of actions and their priorities. A contradiction that, in vulnerable areas (such as the islands and island regions), generates additional predicaments; intensifies inequities on land and at sea; and sets different terms and limitations at the level of political management and planning in individual segments (Sections 5 and 7).

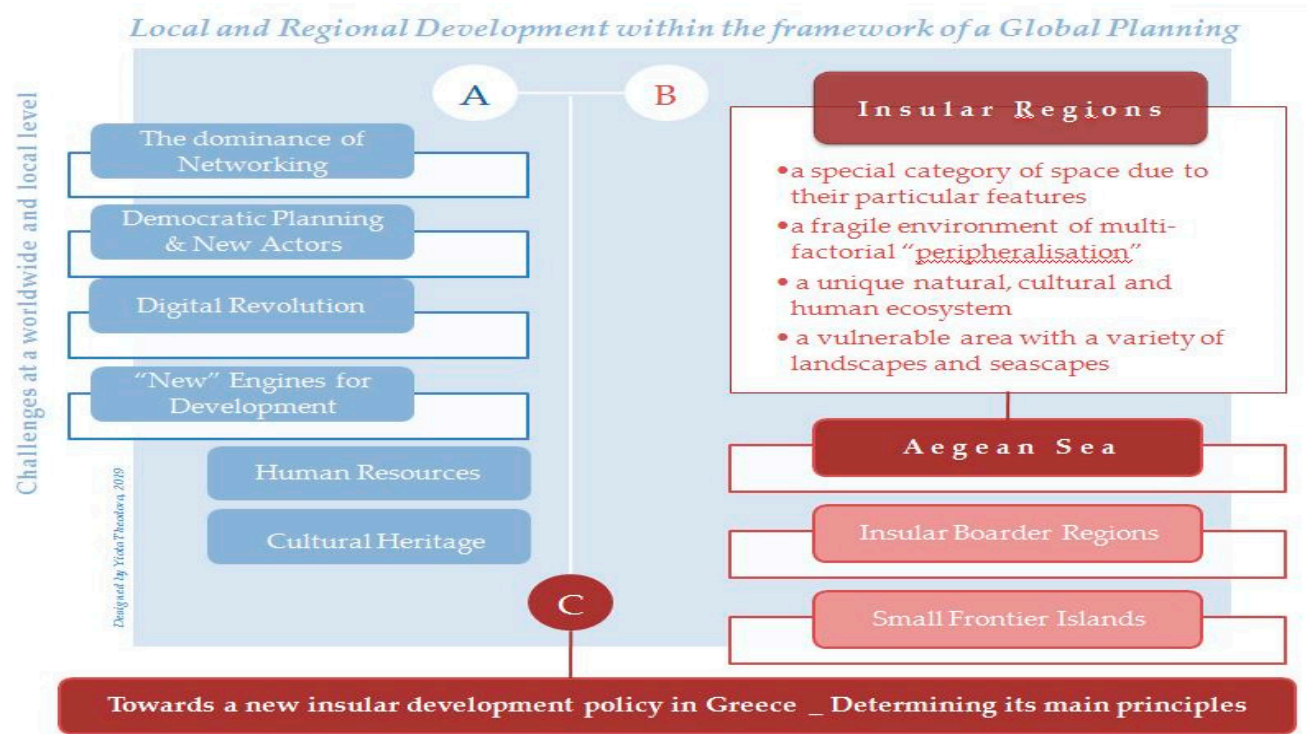

Figure 1. The proposed levels of investigation (designed by Yiota Theodora, 2019).

The second level of research (B) focuses on insular space, seeking to highlight its particular features and to comprehend the problems that it faces ${ }^{1}$ (Section 5). The multiplicity and complexity of this special category of space require a special approach to protection, management, development issues. This is an environment where networking, participatory design, use of modern technologies and management of the human resources available and cultural heritage of ten remain as intentions or are faced with implementation hindrances. This is particularly the case for small isolated or border islands, where distance from dynamic areas of the insular or continental space and the inability of local governments and communities to adapt to the new facts and utilize innovative management and planning practices, impede their development $[13,21]$ (Sections 4 and 5).

In order to avoid a more theoretical approach to insular space management and planning, which lacks a practical basis, for this level (B) we also make use of the conclusions drawn from the first phase of our ongoing research in the Aegean (Sections 2.2 and 6). Apart from this specific research, a key part in formulating the relevant considerations is played by the author's experience in spatial development/sectoral planning from her academic work (research and teaching experience) at the School of Architecture of the NTUA [4,5,14,15,22,23], mainly over the past ten years (Figure 2). At a time of particular significance for Greece, when the planning, socio-economic programming and administration system is undergoing an attempted "modernization" and harmonization with European guidelines, we can ascertain that special categories of space with a dominant role in the developmental prospects of the country continue to be managed in a fragmentary fashion and independently of this system. Insular space is one such case quite paradoxically, as it occurs in a coastal country with a large insular part $[2,4,10,14,20,22]$ (Sections 5-7).

It is deemed that, for the optimum transition from levels (A) and (B) to (C) and in order to make the best possible use of the conclusions in formulating an insular policy, the key prerequisites are: (i) To correlate the three levels organically into the context of current conditions and circumstances on an

1 e.g., encirclement by the sea, proximity, accessibility, the blend of characteristics, depopulation, seasonality in social and economic life, the arid dry landscapes, vulnerability to environmental challenges. 
international and a national level, due to changing conditions and needs. Thus, the effectiveness of an insular policy (and any policy) depends on its flexibly adaptation to the current conditions and trends. This actually requires special monitoring and evaluation means, and correlation to a broader framework of spatial and sectoral design; (ii) to establish a concurrent study of land and marine parts of insular space, in direct ongoing function with the continental space (Supplementary Materials) (Figures 1-3) (Section 7).

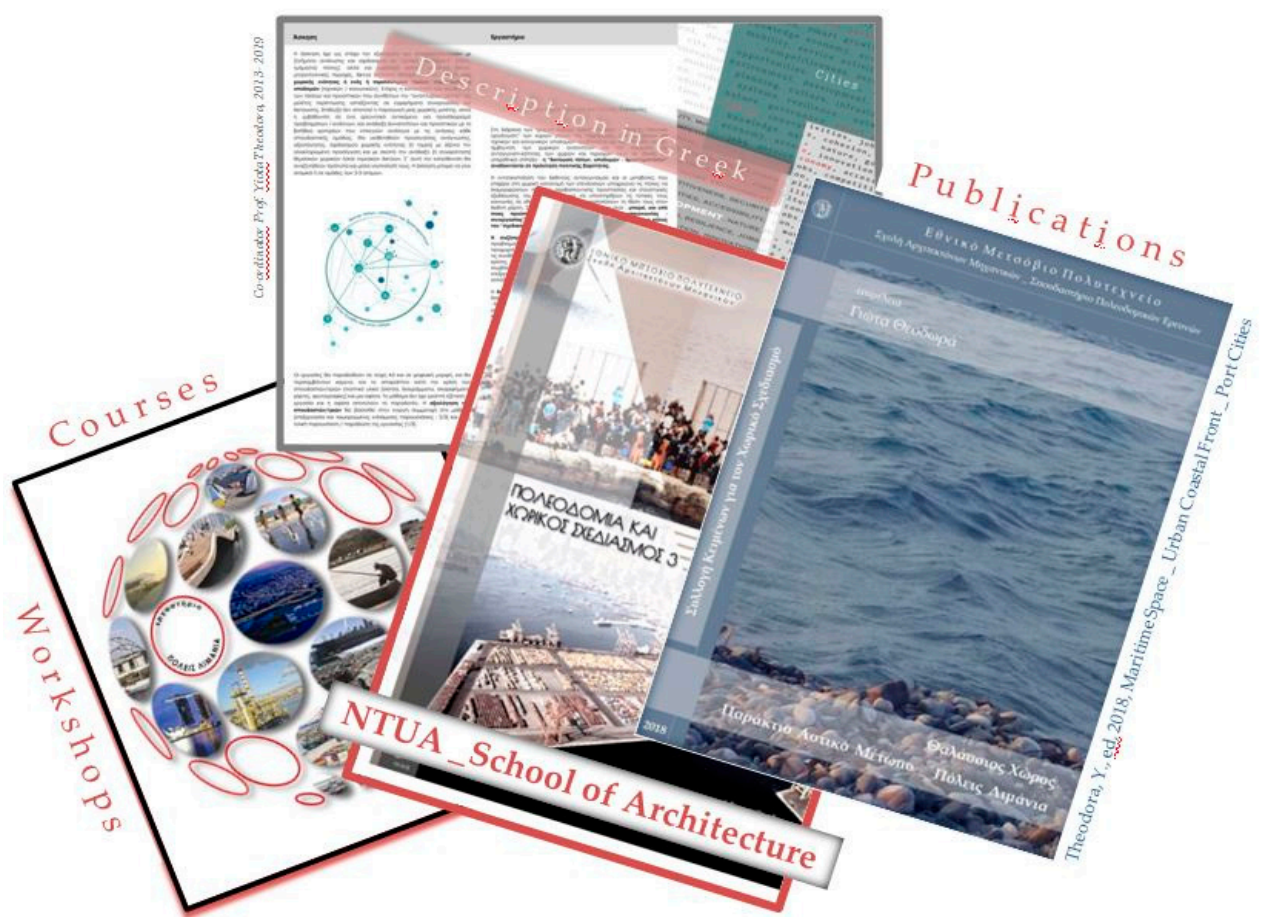

Figure 2. Academic activity and publications on maritime spatial planning, the coastal/insular policy, and global spatial networks local communities (coordinator and editor Yiota Theodora 2013-2019).

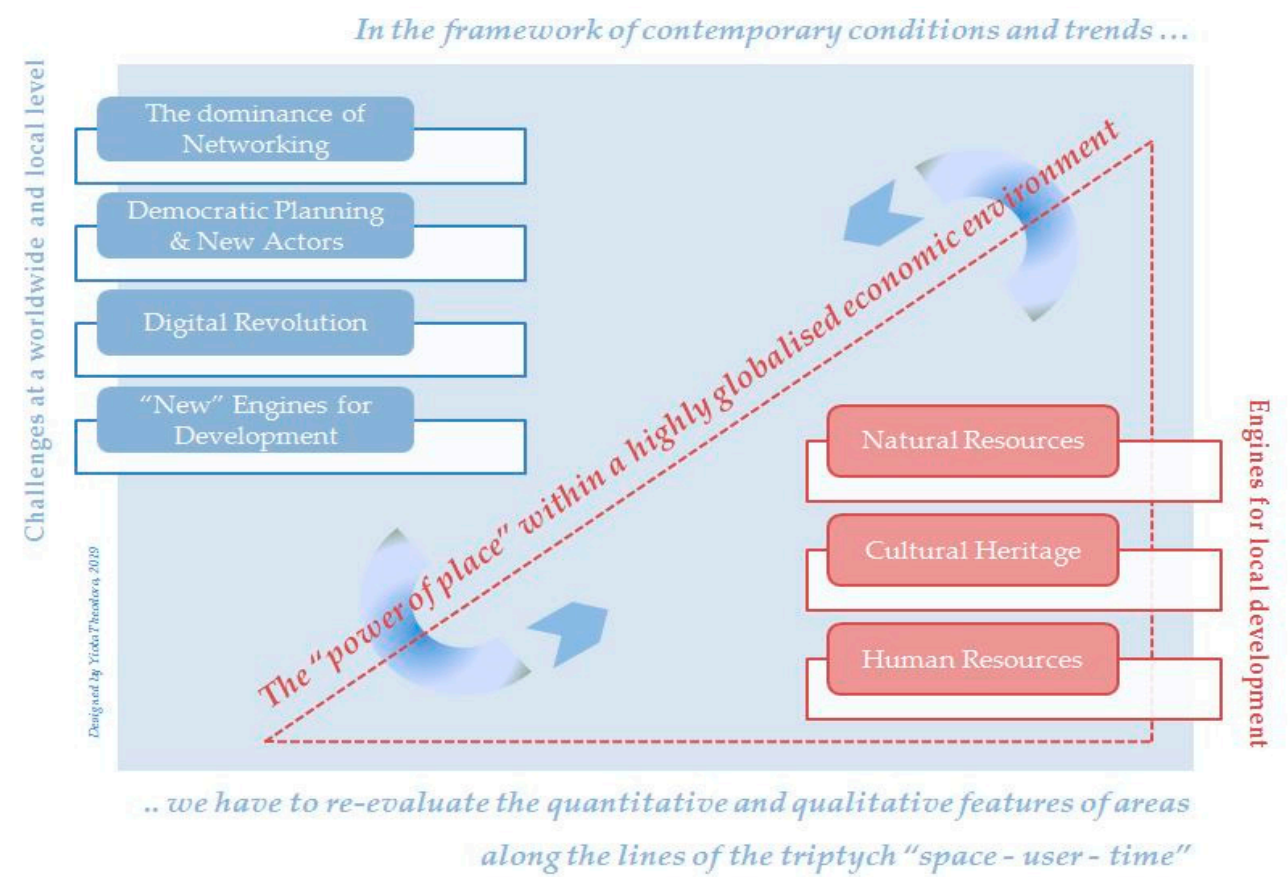

Figure 3. Global-local Interactions—-the power of place (designed by Yiota Theodora, 2019). 
Moreover, the transition from level (A) to level (B) is not always easy, or self-explanatory, or equally successful. This is linked to the relationship between the global and the local, and the interaction between overlying and underlying geographical scales of planning, hence influencing insular policy (Figure 3). This is a very interesting conclusion for Greece; where the lack of insular space continuity coupled with the coexistence of areas of different dynamics create a heterogeneous space. In such a fragmented environment, spaces do not display the same resilience or adaptability, nor do they always have the required knowledge or appropriate infrastructure to successfully implement innovative strategies, tools and procedures for spatial management and development. In such special cases, therefore, such as the insular space, the study of local levels acquires particular interest $[13,20]$. Specifically, defining the best spatial scale in order to evaluate as safely as possible their ability to use the available knowledge and contribute to its evolution and to the production of new knowledge, which, at a later stage, could be utilised in corresponding circumstances, feeding into the overall consideration on a national and supranational level. In the case of Greece, the terms on which the transition from the whole to the partial and vice versa is attempted, as well as the evaluation of their effectiveness in the development of places constitute the objects of discussion. Based to the above, insular space could constitute a challenging field of investigation (Sections 5 and 6).

\subsection{Aegean Sea-A Challenging Place for Research}

This research investigates the specificities of the Aegean Sea in an attempt to seek ways to sustainably develop its vulnerable areas. Namely, islands and insular areas that are under intense pressure of degradation, but which also have comparative advantages, which could be leveraged as development drivers. A solution is sought for setting up knowledge and culture networks of supralocal reach. The proposed "key" development drivers are the local human resources and cultural heritage. A proposal that has its theoretical basis on the model of the "endogenous development", a down-up developmental approach based on decentralization, local decision making and the strengthening of local entrepreneurship and competitiveness of local sectors, through actions forming spatial, sectoral and social networks of collaboration and communication among places $[6,8,13,24,25]$.

Our interest is focused on border regions with a pilot reference field of small remote islands; vulnerable places, which move from the margin to the focus of research interest. The reason is the uniqueness of their natural/cultural wealth in combination with the increasing abandonment they experience coupled with the threat of their identity alteration. The "new" challenge from a planning point of view is to transform these vulnerable places from satellites of dynamic insular or continental regions to hubs of spatio-functional collaboration networks of supralocal reach, with respect for their uniqueness $[5,13,22]$. To this end, in the framework of the research, an attempt is made to record the quantitative and qualitative data (geomorphological, spatial, social, and economic) focusing on the elements of nature, culture and employment of local population. As local development is proposed through the organisation of collaboration networks, it is attempted to classify these places based on location, population and infrastructures criteria placing emphasis on forms of education and culture, while also recording agencies that are active in natural-cultural heritage, education, research [11]. In the third stage we use criteria to select the spatial units that will be the pilot fields of investigation, which will certainly include at least one small remote island. Steps have already been taken to this direction and research has been organized on the level of islands (i.e., questionnaires, cartography materials).

The spatial fields of this research are: (i) The Aegean Sea; (ii) its border regions; (iii) small remote islands. At this stage we are drawing on conclusions from the first level and expect the debate to be enriched by the subsequent spatial levels at a later phase, mainly in terms of defining the tools and indices used to assess and measure the dynamics of vulnerable regions through the definition of their radius of influence on a (trans)-regional/supranational level.

The contribution of the ongoing research in the Aegean Sea is considered to be important at this phase for two basic reasons. Firstly, because it confirms that the sea continues to constitute a barrier, especially to isolate small and frontier islands. Secondly, but equally important, it makes clear that if 
islands and insular regions are to play a vital role within a network-organised environment where knowledge economy prevails, we need to change the way we view their development, redefine the methodological approach framework and set new evaluation criteria of the "insular phenomenon". The crucial issue for insular space's development is: How to use best experience in its units and how local level can generate knowledge to feed the discussion on establishing a cohesive insular policy for Greece (Sections 5-7).

\section{In Line with Contemporary Conditions at a Worldwide Level-The Question}

Mainly over the past twenty years, a new framework of conditions and trends has developed at an international level with multiple effects on places and local societies. Its dominant features are:

- A globalised environment with network organisation being a prevailing feature;

- Constantly increasing population mobility in conjunction with the appearance of new flows of people, commodities and capital;

- The formation of powerful decision-making centres;

- The concentration of services and employment of international reach in developed and less developed areas of the planet.

Under such conditions of spatial-functional changes and reformations, polarisation becomes more intense, as do socio-economic inequities, while environmental (and other) impacts of climate change are visible at all spatial levels, with a differentiation of needs, demands and priorities in each instance imposing changes on the concept of regulation and organisation of space $[4,8]$.

In this highly mutable framework, the particular interest of spatial planning is focused on issues such as:

1. Urban development and the management of natural, cultural and structural environment;

2. Planning for special categories of space (e.g., coastal, insular, mountainous, trans-border, historical cities and settlements);

3. Organisation of new urban structures and regulating urban sprawl and concentration;

4. Encouraging of collaborations and forming of spatial/sectoral/social networks;

5. Development of partnership relationship between the city and the countryside;

6. Management of issues on a broader spatial scale (e.g., employment, poverty, resilience, climate change);

7. Environmental planning;

8. Planning infrastructure systems (production, technical, social) as a means of spatial development (energy, knowledge, innovation, culture and others);

9. Participatory planning and the rise of new players and governance structures.

At the same time, the excessive concentration of the population in cities in conjunction with the abandonment of the countryside, particularly in vulnerable regional areas, such as island, mountain, frontier, border areas intensify the interest in dealing with multiple and complex spatial problems which set out new terms, limitations and priorities in organising human activities and functions both on land and at sea.

Under these circumstances-with the issue of: For whom is development, where should it take place and under what terms remaining "open"- the question is: How do we plan at the various levels and for various categories of space, protecting the history and identities of settlements, cities and regions and ensuring local development in terms of social justice and sustainability in a highly globalised economic environment? [4] The issue arises of how to set up new research methodology and planning, application and monitoring pathways, issues that are not easy to define, commonly accept and practice. Particularly at times of economic recession, where modernisations attempted are mainly based on an uncritical adoption of developmental models and actions of a methodically organised 
depreciation of the spatial dimension, undermining acquis that for years had been promoted as a prerequisite for living under conditions of urgency-oftentimes without any effective consultation. So the matter remains: Who plans/decides, when, why, where in space, for whom and on what terms? [16] (Section 7).

\section{Local and Regional Development within the Framework of a Global Planning Perspective-New Challenges under the Conditions of Transitory Economy and the Digital Revolution}

The differentiation of the model of economic activity within the framework of the "intangible economy" has affected the process of urban and regional development, strengthening certain places (settlements, cities and regions) more than others; and marking dramatic shifts in their models of organisation, economic administration, coordination and administration [1,3,6-9,11,12]. Of particular interest are those settlements and cities (small or medium in size) within insular and/or mountain areas with significant natural and cultural wealth where, in an attempt to deal with their downward developmental turn and to increase their attractiveness, they adopt models that focus on sectors (e.g., tourism, recreation) which increase the risk of altering their character and the uniqueness of their identity. A choice which is constantly reinforced in an age where increasing competitiveness and changes brought about by the spatial distribution of investments obliges governments of countries to formulate strategies as to the role of their cities and regions in order to support their local societies and strengthen their position on the global map (Figure 3). The issue is: How can they make use of the authenticity of place within the framework of global planning perspective where, increasingly, spatial development is sought solely through actions commercializing their unique features? $[4,5,10]$ (Supplementary Materials).

Within the framework of a debate on topics such as: "globalisation vs. locality", "tradition vs. modernisation", or "sustainable development vs. economic growth", in fact it is proved that new trends require policies and practices of planning emphasizing the socio-economic processes on the basis of a multi-variable approach on spatial issues included in mutable dynamic sat all spatial levels, focusing on local unique features and encouraging synergistic actions and networking, starting from the social and economic base $[1,8,9]$. Under such circumstances, where what is sought continues to be ensuring spatial/socio-economic cohesion; reducing inequities; and strengthening social participation, the multiplicity and multi-complexity of contemporary spatial problems makes it necessary to approach and implement planning through the organisation of spatio-functional networks for communication/collaboration in the varied levels/categories of space (irrespective of administrative boundaries and national borders) $[8,13]$. Thus networking (in spatial, sectoral, social terms) constitutes a challenge within the framework of setting out developmental strategies/tools and comes to the forefront of the agenda in social discourse, particularly as far as concerns the terms under which this is attempted, in order to ensure the authenticity of the areas and the strengthening of local communities. Within the framework of global planning, the local scale gains fresh gravity in the management of resources and in spatial regulation [11]. As such, loci gain a new crucial aspect in establishing the spatial policies. At the same time, one can ascertain a turn towards new forms of participatory governance, where both official and non-official institutions, mechanisms, processes, provide those involved with the capability to participate by setting down their views, needs and vision. All the above trends require that the population should be well educated $[4,6,16,26,27]$.

With effectiveness and justice sought at all levels/categories of space, the key challenges with respect to spatial planning constitute the management of: (i) The increasing trends to create networks in correlation with strengthening the role of the local scale; (ii) a new system of socially active persons which redefines existing governance structures requiring flexible participatory processes at all stages of spatial regulation (decision, design, implementation, monitoring); (iii) new innovative more user-friendly digital technology media for spatial analysis, evaluation and planning (even when users aren't experts); and (iv) the ever-increasing interest in the utilization of human resources and cultural heritage as "engines" for local and regional development $[4,6,16,20]$ (Figure 3). 


\subsection{The Dominance of Spatial/Sectoral/Social Networks and the Power of Place-New Realities of New Geographies}

Places (settlements, cities, areas) do not function in isolation or even autonomously. They are hubs of broader spatial/functional networks of various forms and dynamics in conjunction with the relations between them (collaboration, competition, complementarity), which can be at the same level or organised hierarchically and expressed through various flow networks depending on their quality and capacity. In line with the constantly increasing globalisation of economies and the new geographies, accompanying this, the view that every country constitutes a closed autonomous system of settlements, cities and regions, the hierarchy of which is defined endogenously, is old-fashioned. Over the past few years, it is generally increasingly recognised at the level of both theory and practice that, depending on their developmental reach, places participate in a worldwide division of labour, which is carried out through transnational investments. This creates an invisible but tangible production-distribution network on an international level, whose hub points are cities of international renown, while immediately below this there are urban networks, each of which hosts a specific combination of actions and serves strategic choices of multinationals on a trans-regional and local level. Segments of space which for some reason did not manage to ensure their desired positions display an unstable development in this dynamically evolving urban network and are controlled by external decision centres, which can define both their current and future state. Communications networks (e.g., systems for transport, telecommunications, etc.) and the effect of new modern technology can help develop interconnections [4,11].

At the same time, experience shows that population size and the position of cities in the national administration network do not constitute necessary and sufficient conditions for their inclusion in international spatial and functional networks $[3,7,8,12]$. The nature and number of infrastructures and activities of supra-local significance gathered therein and the degree to which they are correlated to each other in conjunction with their high degree of accessibility and their geopolitical position can constitute a powerful comparative advantage, particularly in cities and settlements of medium or smaller size. Cities that function as "entrance/exit gateways" present particular interest, as their dynamics are not linked solely to the transport systems they have at their disposal, but also to activities/infrastructure of supra-local reach in sectors including education, research, culture and tourism. These cities gain additional significance when they are located in rural areas in border and frontier groupings of the continental or insular space due to the dynamics they gain through their varied correlations with settlements in their broader zones of influence, which function as their satellites [11].

On the basis of these constantly expanding trends for increasing new urban correlations in the insular and continental space, throughout the last fifteen years in particular, cities and settlements have gained greater reach through ever expanding spatial units (intermunicipal, interregional and interstate) bringing back to the discussion a host of issues that need to be dealt with, particularly on the level of implementing developmental choices. Locality is promoted as a solution for dealing with the risk of alteration and assimilation of space when, particularly under recession conditions, the broader ideology that deals with places as products to be consumed continues to be dominant. So to evaluate their varied qualities in order to protect them and creatively re-include them in the everyday life of local societies goes counter to mentalities and issues of moral stance, which frequently draw citizens away from history and tradition by adopting, either forms of imposed protection through inflexible mechanisms and an institutional framework, or programmes utilising state or private agencies that do not always line up with needs and priorities of the local population. They thus return to the forefront of the discussion on planning practices, which are based on a model of "endogenous development", in line with which what is sought is the sustainable management of the particular features of places to the benefit of their societies with planning from the bottom up. Such an endeavour, depending on the instance, can require the: (i) Focusing on crucial resources (natural, cultural, human) and ensuring they are protected and properly used; (ii) designating the boundaries for preserving crucial natural procedures (such as issues of carrying capacity, resilience, 
adaptability, selectivity) placing emphasis on the qualitative differentiation and not on quantitative advantage through initiatives that support knowledge, research and the use of new technologies [6]. This is a model which comes to replace, to a great extent, the old model of political development for the classic central regional policy (top-down control) through a rationale of strengthening the bottom-up collaboration and networking in order to promote a type of development that is better adapted to the character and the endogenous dynamics of the regions. Irrespective of any potential weaknesses, the model of "endogenous development" strengthens the meaning of places within the framework of a global planning perspective. Its implementation is of particular interest especially in vulnerable areas of the continental or insular space of geopolitical importance and natural-cultural wealth. Consequently in instances whereby the population is retained in rural areas, upgrading local factors and reinforcing entrepreneurship can be achieved with greater ease through the management of the "power of place" in a reasonable organisation of networks of collaboration and exchange of experience and know-how $[5,7,11,26]$ (Figure 3).

\subsection{Democratic Planning in a System of New Social Actors}

Under conditions where both networking and locality dominate, what is required at the level of setting guidelines for developmental strategies is to establish democratic planning by encouraging active participation, incorporating non-experts, i.e.,citizens who have no specialized knowledge, but who know better problems and prospects of their places, in the process of jointly evaluating the quantitative and qualitative features of areas along the lines of the triptych space-user-time $[4,16]$.

Modern conditions/conjunctions have altered all givens, demands and priorities. At the same time, through a study of trends and dynamics taking shape internationally on issues of spatial management and planning, a plethora of new forms of urban governance have started to come into prominence, which, besides the official agencies, include involvement by new actors. Increasingly greater numbers of non-governmental people involved, in various forms, start to carry out a crucial role in the decision-making process, establishing a new social network of actors. The role of citizens in these new governance structures presents a classification depending on where the initiative arises (governmental or other body) and the goal of their participation (natural action or an activity with a political bent).

Despite the problems, it is a fact that planning from being an exercise for structuring a collective course, indivisibly dependent on the knowledge and culture of the researcher/planner, is gradually turning to a new rationale, which increasing recognises that nobody has the wisdom or capacity to make decisions that affect society without input from said society, i.e., to schedule and plan for citizens in their absence. Spatial problems are complex problems. Because of this, planning should open a discussion; not shape defensive tools; contribute to formulate a common position; and allow collaboration in a democratic environment, where it has been ensured that all social groups are represented. So to investigate the field, beyond technocratic input, requires the involvement of citizens, who must undertake responsible action, because only by making use of their knowledge, inspiration and influence in the decision-making process can the best possible results be ensured. Their participation, therefore, in planning must be encouraged and sought, by adopting innovative participatory procedures for which local administration will be responsible and must be expanded through communications structures to residents of other places, who face corresponding problems, facilitating thus the diffusion of experience and best practices. Decisions taken within the framework of a democratic discussion are far less likely to be questioned, while such discussions expand planning options available and increase the possibility for planning results to be superior $[4,20,21]$.

\subsection{The Role of Digital Technology in Spatial Analysis andManagement-Perspectives and Risks}

In an age of network organisation-where the multiplicity and complexity of spatial matters concern ever broader geographical scales and more complex structures of participatory planning-the use of digital technology media is more necessary than ever in spatial analysis, management and 
planning; as it allows multi-criteria researches of qualitative and quantitative variables. Irrespective of any reservations regarding their effectiveness in the perception of space and the evaluation of its dynamics, we will agree that recording and monitoring the evolution of spatial phenomena is impossible without the use of analytical, compositional and imaging media, especially within the new worldwide framework of large data and trends (Section 3).

Under the conditions of the digital revolution, modern technology and geo-information media (headed by geographical data systems and digital analysis systems) constitute a basic mechanism to approach the manifold dimensions of space and to comprehend the trends, prospects and risks within the framework of urban, regional and environmental planning and urban synthesis/design being attempted. Digital media allow us to depict segments of the surface of the land and marine space in two or three dimensions by adopting a variety of methods [28,29]. The practical interest in their use lies in the variety of approaches and mapping they provide, which allow researchers and planners to create and process themed and analytical maps "visualising" the data available. The advantages of their use mainly include: (i) Measurement, comparison, correlation of quantitative and qualitative indices, mapping and monitoring over time; (ii) recording, evaluation and projection of experiences; (iii) access to difficult-to-access segments of space [28,29]; (iv) (re)production of various conceptual images/simulations; (v) setting up spatial/sectoral/societal networks of collaboration/communication [13-15]; and (vi) organising structures to provide information, institute democratic discussion, and interactive participation [20,21]. However: On what terms and to whose benefit?

Without doubting the contribution of digital technology to spatial management, the risk of such media being used as a mechanism to serve the better-organised groups or for them to exercise influence and formulate the citizen's vision should be noted. This brings to the forefront questions regarding the contribution of digital technology to drafting development strategies and highlighting planning practices. Technology has no will. Its use therefore depends on who uses it and for what purpose. A condition that includes the risk of a subjective stance, as the values systems, culture and interests of the users in each instance affect the orientation of the developmental choices defining, when it comes down to it, the terms of planning. In order for digital technology to function as an essential means to assist in spatial planning it is necessary to: (i) Be disciplined in the choice of tools and methods used, with respect to local identity, sustainable management of resources, and jointly evaluating the real local needs of the population; (ii) establish interdisciplinary scientific discussion to promote flexible media which are accessible even to non-experts; and (iii) formulate strategic digital technology to serve planning in a flexible manner within the framework of a broader spatial policy for development $[4,16]$.

\subsection{Human Resources and Cultural Heritage as Catalysts for Local and Regional Development}

Under conditions where the learning society and the knowledge economy dominate, the role of human resources in spatial development needs to be redefined. Emphasis is placed on supporting the production process and regaining entrepreneurial creativity through networking. Attention is now shifting to citizens, who are called to contribute to addressing the new realities through socio-economic, cultural and political innovations. Citizens well informed, educated and aware, who understand the importance of preserving the authenticity and of feeding the imagination, and also have the ability to combine knowledge, for the purpose of either making it useful for specific applications, or adding new value to it. These are conditions that are not guaranteed automatically, but only through actions for changing ways of thinking and pursuits. To this end education must play a crucial role, as, led by knowledge, it enriches the interests of citizens, shapes ideology, culture and social conscience, contributing in a variety of ways to the establishment of a new creative class. This shall not be motivated solely from material benefits, but shall select and seek to live in more qualitative, creative, exhilarating places $[6,24,25]$.

Parallel to the above trend, interest in cultural heritage continues to grow; and is ever more strongly linked to creativity. Particularly that dimension which exceeds the material to include the 
living expressions and traditions of countless groups and communities throughout the entire world, which have inherited them from their forebears and transmit them to their descendants, in most instances from mouth to mouth. We are discussing intangible cultural heritage ${ }^{2}$, which, due to the wealth of its cultural objects, appears to be able to ensure to the agent of its expression the sense of identity and, subsequently, to the extent that he or she masters it and can recreate it. As a living social phenomenon, intangible heritage cannot be safeguarded and refreshed in a museum manner ${ }^{3}$. This is the reason why management of cultural heritage should be based on practices of physical planning targeting the introduction of its elements (tangible and intangible) into space, but also the everyday reality of residents and visitors $[5,13-15,18,29]$.

\section{Insular Space-A Vulnerable Area of Dynamic Places and Varied Landscapes}

Insular areas constitute a special category of space due to their particular features, which make them different from other spatial entities and which become reasons for geographical and socio-economic isolation and for increasing inequities on a local and trans-regional level. These features are also encountered in spatial entities within developed areas. However, in insular areas their concentration and potency are far greater, particularly in instances of small and remote islands. This makes it imperative that when they are evaluated as part of developmental policy/spatial planning they should be counted in this vulnerable area of space. We are referring mainly to:

1. Spatial factors that concern geographical position and the particular features of their natural and manmade environment;

2. Demographic factors (aging population, limited dynamic, seasonal variation in population to name a few);

3. Economic factors linked mainly to supply and demand, high cost of production and small market, insufficient work force skills, insufficient (or non-existent) development of investment and a preference towards seasonal activities (like tourism);

4. Social factors mainly related to deficiencies at a level of technical/societal infrastructures and services, due to the large cost created by the negative economies of scale. In fact, every island, no matter how small, requires a full set of infrastructures and services, which are necessary for its development, however much this might not be excused by its population size. No island can really depend on the infrastructures of a developed neighbouring area, particularly when said island is isolated.

Indubitably, we are discussing about an exceptionally fragile environment of multi-factorial "peripheralisation" 4 , which renders it vulnerable. Such a "peripheralisation" is related to: (i) Distance from central developed areas; (ii) the degree of accessibility; (iii) the dynamics of the collaboration relationships through developing networks for the flow of goods, people, capital, as well as the level of

2 We consider intangible cultural assets to be expressions, activities, knowledge and information, such as myths, customs, oral traditions, dances, actions, music, songs, skills or techniques, which constitute testimony of the traditional folk and scholarly culture (no. 2 para. v, L. 3028/2002 on the Protection of Antiquities and Cultural Heritage in general, GG 153 A/28-6-2002). The sectors of intangible cultural heritage include the know-how connected to traditional handicrafts [weaving, pottery making, wood ship-building skills and others]. Greece ratified the UNESCO Treaty for the Protection of "intangible cultural heritage" in 2006 [GG275/22-12-2006, Law no. 3521].

3 Available online: http://www.unesco-hellas.gr/gr/3_5_2.htm, http://www.unesco.org/culture/languages-atlas (accessed on 10 May 2017).

4 "Peripheralisation" one of the most widely spread concepts in issues of spatial development of vulnerable regions. It can be measured using simple or complex indices. The most accepted method of its measurement at an E.U. level is the average transit time using road, train or air transport to each of the major centres of economic activity of the community space (see European Commission, Competitiveness and Cohesion: the trends in the periphery (fifth periodic report on social and economic conditions and the development of the regions of the Community, p. 112). At an E.U. level, areas are considered peripheral when they are frontier and coastal particular in insular space, which appear to be cut off from the main body of productive activities. 
development of each of these networks and the degree to which they are depended on decisions taken in other more central areas of insular or mainland space.

The territorial multiple dispersion of insular space, the heterogeneity of its segments (size and dynamics of islands) and the differences in the relationships among them (kinds, quality, frequency of flows and networks) as well as the extent of their dependence on the continental space, in conjunction with the variety of inherent weaknesses and developmental prospects compose a field where crucial matters that should be dealt co-exist. In this field, places of particular dynamics are encountered under conditions of a variety of landscapes-not necessarily with harmonious relations between them. Landscape is the image of a place. Thus, the way in which it is perceived depends on culture and the particular characteristics of population groups. Therefore arises an issue of raising awareness on parameters concerning protection and management of the features of places. In theory and in practice there are many points of view on how to perceive and present the features and the dynamics of a place, through which different images can arise. From these images of a place can be derived many (extant or not) landscapes of spatial/sectoral/social character (e.g., urban, rural, natural, historical; or accordingly to their infrastructure industrial, mining, shipping, trade, tourism, recreational; as well as of a special character, such as migrant and refugee flows and facilities [16].

The development of such a special category of space, as that of insular regions, must necessitate a special methodology for research and spatial regulation and allow for the simultaneous approach of matters of general and special character [4]. Within the framework of their planning, insular regions must be dealt with as any other space, but also as a special instance, focusing on parameters that must be taken jointly into consideration otherwise, as proved by evidence, the formation of a strategically integrated island development policy is hampered. These parameters include:

- The coexistence of natural and cultural wealth and sub-standard living conditions (e.g., access difficulties, lack of sufficient infrastructures, phenomena of excessive exploitation of resources, differentiation of the production structure);

- Ecological, socio-economic, cultural boundaries that lessen the carrying capacity of the islands and are also giving them the character of isolation with dominant characteristics a sense of abandonment, social and population decline;

- Various kinds of restrictions that concern geomorphological and ecological factors (i.e., vulnerability to natural disasters, climatic conditions, sensitivity of natural space (coastlines, protection areas and so forth)), which affect the degree of resilience and adaptability of the islands to any risk conditions and events.

On the basis of the foregoing, the management and regulation of insular space (and any other kind of space) should be governed by basic principles, namely: The principle of a single perspective on space; the principle of jointly evaluating the local individual characteristics; and the principle of inextricable correlation of developmental policy and spatial planning. Specifically:

- The principle of a single perspective on space-insular space (as any other kind of space) does not constitute a simple synthesis of lines, shapes or volumes, but it is a living phenomenon; an environment where societies live and create history. As either resources or players are introduced into the developmental process they constitute an exploitation element which will lead to the creation of income and wealth. At the same time, insular space, due to the individual differences in each of its units multiplicity of natural features and other factors, which can be included under the general title historical evolution, constitutes one additional factor, which contributes to creating inequities relating to economic but also access to elements that shape the preconditions ensuring a desirable and socially-acceptable standard of living. So, spatial issues are not simply technical, but strongly environmental, socio-economic and political. Their approach therefore should not-and must not—be attempted along one sole dimension and in a fragmentary manner. They should be studied and evaluated on the basis of their dynamic consideration while simultaneously monitoring crucial fixed values that are related directly 
or indirectly with the environment (natural/cultural), space (land/marine), society, economy, system of administration/decentralization, the legislative framework, the land policy and the investment policy.

- The principle of jointly evaluating the local individual characteristics-differentiations between places and time, require a simultaneous approach of the special nature of spatial sub-entities (e.g., marine/submarine, coastal, mountain, urban (urban network, network of port cities), periurban and outer-urban areas) which compose them on every geographical scale. In the case of insular areas, in order to best deal with the risks of unequal development due to differentiations in productive structure, environmental decline, isolation and "peripheralisation", must be evaluated: The difficulty of access, their isolation (great distance), and their small size.

- The principle of inextricable correlation of developmental policy and spatial planning-accepting that there can be no development without planning; proposal without evaluation of the current situation; intervention without knowledge of the problems and understanding of the underlying causes and reasons they are perpetuated; it is necessary to correlate developmental policy and spatial planning on the basis of understanding their dynamic, multi-level, multi-dimensional, multi-sectoral nature. Exploration should concern various spatial scales, be linked to the variety and number of sectors of human activity and be approached within a framework of multiple dimensions, including political, socio-economic, environmental, spatial, sectoral. At the same time, recognising that planning constitutes a process of political significance, due to the multiple, often differentiated(in each instance and over time) influence on places and societies, we support the need for close contact with the field of intervention and the participants in each instance (e.g., administration, agencies, investors, citizens). Unfortunately, despite attempts to date, it can be ascertained that scientific discussions do not always take place with sufficient documentation, while participatory structures and procedures in the majority of instances are forgotten in the space between intent and implementation and monitoring, creating significant problems in practice $[20,21]$. Therefore, the following constitute a challenge and a wager on the level of spatial development and planning

- The simultaneous use of space as administrative unit(administrative usage), natural element(spatial usage) and also as special spatial group(spatial-functional usage) which requires attention at a management level, either as a developmental factor (given that this is where a significant part of developmental processes take place) or as a vulnerable area if development there is evolving in a negative or undesired manner or is combined with problems that require solution on the basis of a supralocal view irrespective of national borders or administrative boundaries, as in the instance of insular space [4].

- The management of multiple expressions of a new urbanisation, which function in succeeding and complementary fashions and which, despite the variety in their forms, have common elements (tertiarisation, diffusion and networking trends). As, irrespective of spatial scale, cities initially diffuse into the broader space and subsequently, depending on their dynamics and the dynamics of neighbouring cities, wither network forming conurbations or come into the zone of influence of more powerful neighbouring cities functioning as their satellites. A similar picture exists in the urban network of vulnerable areas with special interest in insular areas, where the sea sets special terms and limitations [11].

- The highlighting/making use of the dynamics of rural areas and the new relationship between city and countryside inextricably correlated with constantly-increasing support for the role of small and medium size cities and their significance in producing/regulating space, especially when these constitute entrance/exit gateways for mainland and/or insular space [2].

- The need for a simultaneous study of mainland, insular and maritime areas, which sets new issues at the level of administrative structure and research methodology of spatial analysis, management and monitoring [10]. 
- The jointly evaluation of the increasing dominance of spatial/sectoral/social networking and the greater role of the local scale in the conditions of global planning-as trends with multiple consequences of a local and supra-local nature, which impose the simultaneous approach of territorial (mainland and insular) and maritime spatial entities [2,11,22].

- The rise of new systems of social actors and governance structures under conditions of the digital revolution, focusing interest on establishing democratic discussion to ensure collaboration between those involved and the best possible representation of various social groups $[4,16,20,21]$.

- The adoption of the model of "endogenous development" for the best possible use of local comparative advantages for settlements, cities and regions showing respect to elements of nature/culture-particularly under the current conditions of global planning and multifaceted economic downturn $[2,5,13]$.

- The dealing with special issues related to the attractiveness and "peripherality" of settlements, cities/areas, which make it necessary to study simultaneous the special spatial units (principle of jointly evaluating local particular features) and the relationships between them $[2,4,11]$.

\section{Aegean Sea: Attempting Local Development through Establishing “Networks of Knowledge and Culture"}

The Greek marine territory constitutes a unique natural, cultural and human ecosystem, which is under strong and multiple pressures due to the coexistence of activities of a supra-local reach, which are often completely at loggerheads with the carrying capacity of its places ${ }^{5}$. At the same time, its geopolitical positionbetween three continents (Europe, Asia, and Africa), particularly influences: The Sicily-Tunisia Passage; the Strait of Otranto; the Dardanelles and the Suez Canal. Its geopolitical position in conjunction with a variety of elements of nature, history and culture it combines, render the Greek marine territory a place attracting many different claims and a great investment interest, with consequences on a national and trans-regional/local level.

Figures 4 and 5 illustrate only some of the diverse perceptions of the Greek marine space, highlighting both its complexity and heterogeneous dynamics of its land and marine segments. Emphasis was placed on factors that exercise pressure on local areas, such as ship traffic density (low density indicated in blue and high density in red) and tourist development loci (Figure 4); as well as refugee and migrant camp areas, and places of energy interest (Figure 5).

In such a diverse space as the Greek insular one, it is established that spatial/sectoral/social networks with international reach become dominant, raising issues about the management of their effects at the level of local societies. It is therefore interesting to look for new alternative forms of networking, which are respectful of local identity and aim at territorial and socio-economic cohesion at an interregional (among islands) and local (island level) scale. Such forms of networking could help manage supralocal issues (such as the effects of climate change or migrant and refugee flows) as well local ones, mainly pertaining to development by leveraging local competitive advantages [5,8,13-15].

The Aegean Sea in particular constitutes an instance of unique interest due to its geostrategic and geo-economic significance; a particular place where qualities and contrasts coexist. The birthplace of one of the first civilisations in the world with a history of millennia; an area hosting places of history, memory and culture, geo-sites [23] representing significant moments of the earth's history ${ }^{6}$; natural ecosystems and elements of folk vernacular tradition and architectural heritage. The above are forming

5 Marine transport (commercial and passenger), mining for fossil fuels, submarine pipelines transferring materials and energy, energy collection centres and renewable resources collection centres, fishing, aquaculture, unified cultural heritage, natural ecosystems and habitat protection areas, military infrastructures, tourism and recreation infrastructures on land and at sea, etc.

6 Geological and geomorphological positions which are major witnesses to earth's long evolution or indicate modern physical or geological processes, which continue to evolve on the surface of the Earth [23] 
landscapes and seascapes of unparalleled beauty and sensitivity that have to be evaluated at local and interregional level (Figure 6).

(a)

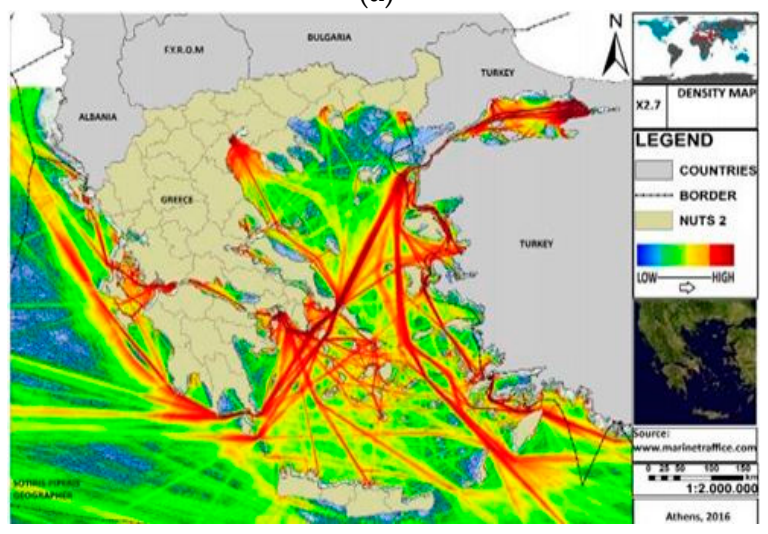

(b)

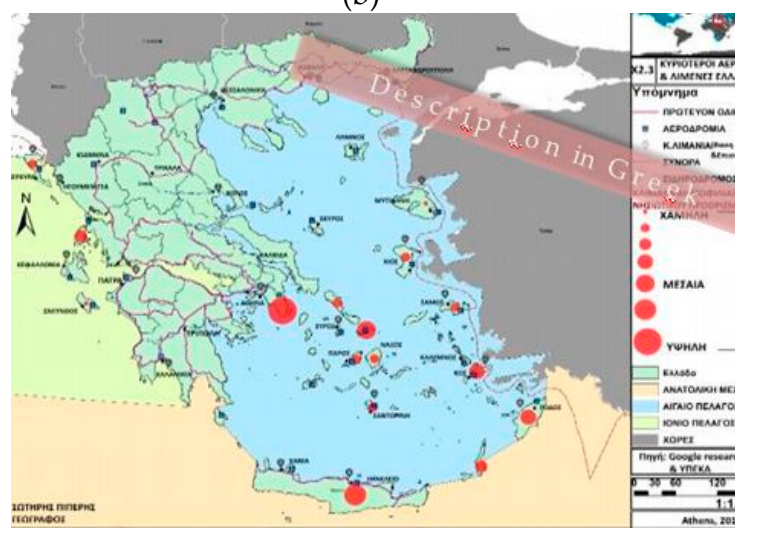

Figure 4. Greek maritime territory-GIS mapping of: (a) Ship traffic density; and (b) tourist development loci [30].

(a)

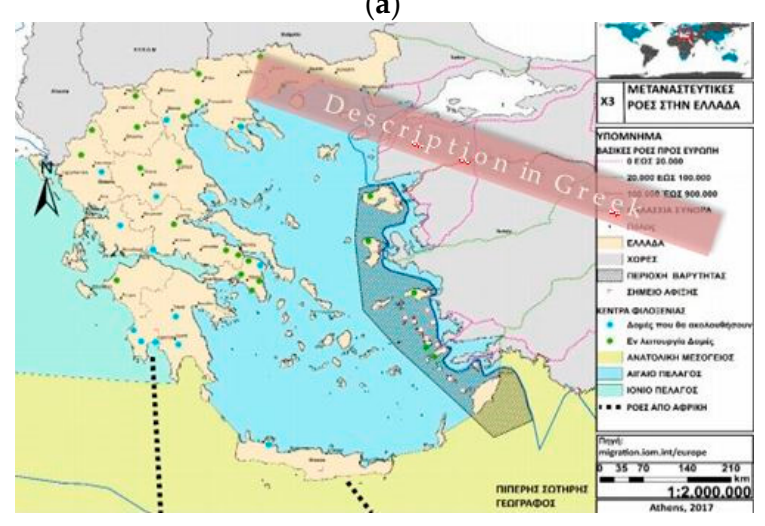

(b)

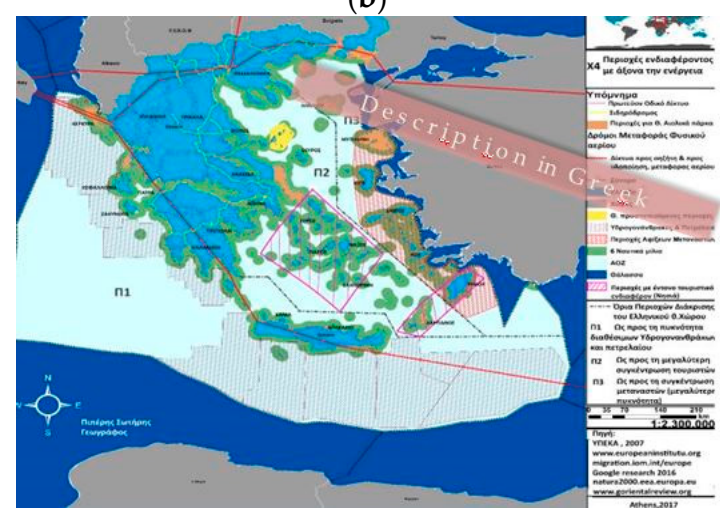

Figure 5. Greek maritime territory-GIS mapping of: (a) Refugee and migrant camp areas; and (b) places of energy interest [30].

The Aegean Sea is a basic entry/exit gateway for Europe from the east (Figure 4a), a connection point of various seas(Black Sea to the Mediterranean (the Dardanelles/Bosphorus, Myrtoon Sea, the Sea of Crete); the Adriatic (Bay of Corinth, Ionian Sea, Myrtoon Sea) and the Red Sea, (Myrtoon Sea, Sea of Crete, and the Suez Canal)) (Figure 7a) and a new energy crossroads for the South-Eastern Mediterranean (Figure 5b). A place which-due to the coexistence of a wealth of land and maritime routes of international significance (trade, maritime, military, energy, migrant, refugee, etc.) - gains new importance as a passage and as a place of settlement. In this place, the Greek islands, with a cultural heritage of multiple historical pasts, must manage the risk of their landscapes ${ }^{7}$ being alteredand their urban network going into decline or being abandoned. The main causes are their degree of accessibility and networking with dynamic areas of mainland/insular space, unregulated tourism development and the planning of energy infrastructures which threaten their ecosystems (Figures 6 and 7).

7 e.g., submarine, volcanic/geomorphological formations, natural/cultural/historical ecosystems on terrestrial/marine/ submarine space, rural landscapes, traditional settlements and historical city centres, historical monuments and groupings. 


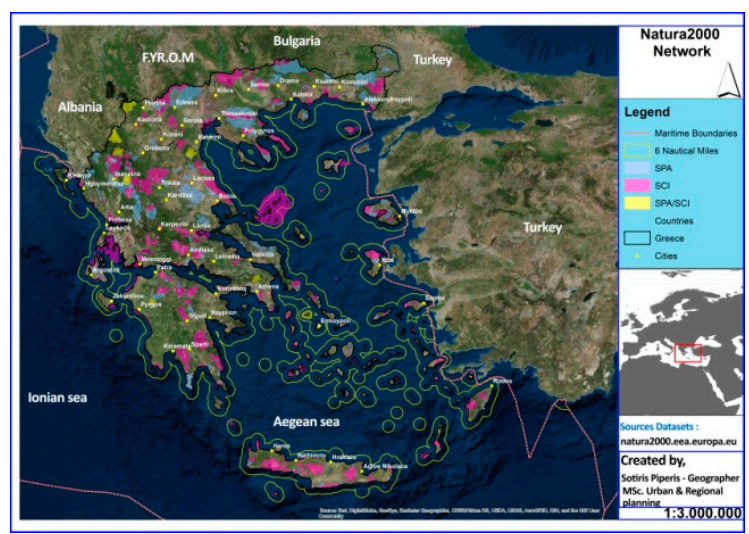

(a)

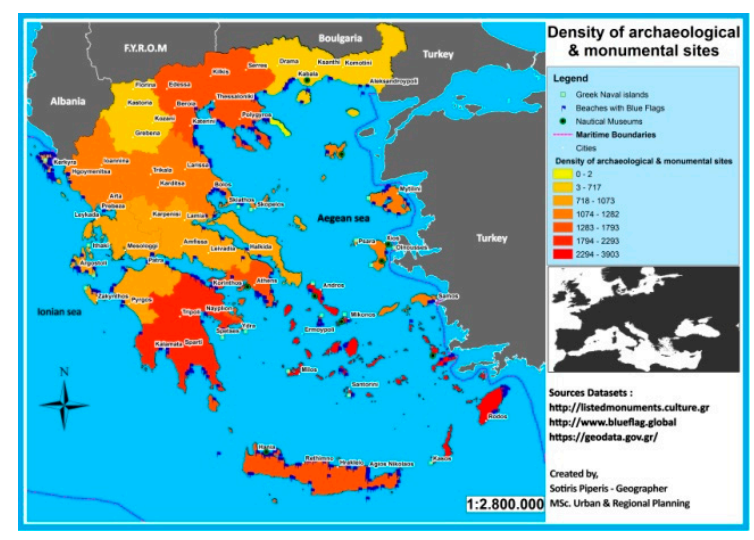

(b)

Figure 6. Aegean Sea-GIS mapping of: (a) Natura 2000 Network; and (b) archaeological and monumental sites [31].

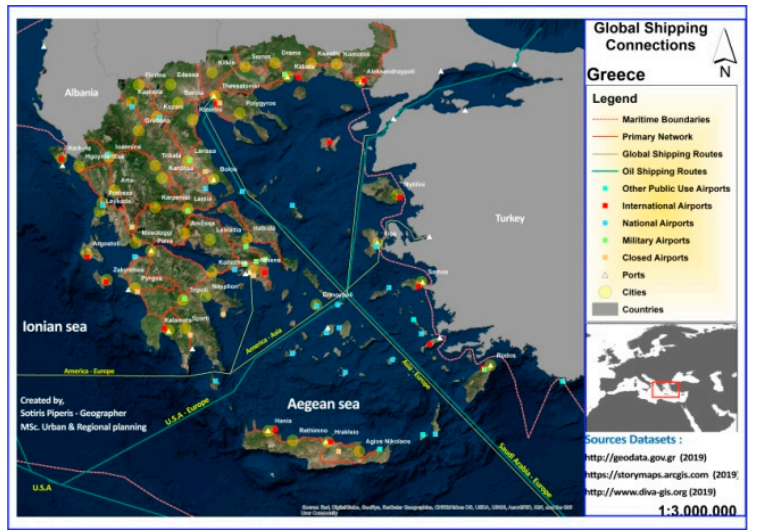

(a)

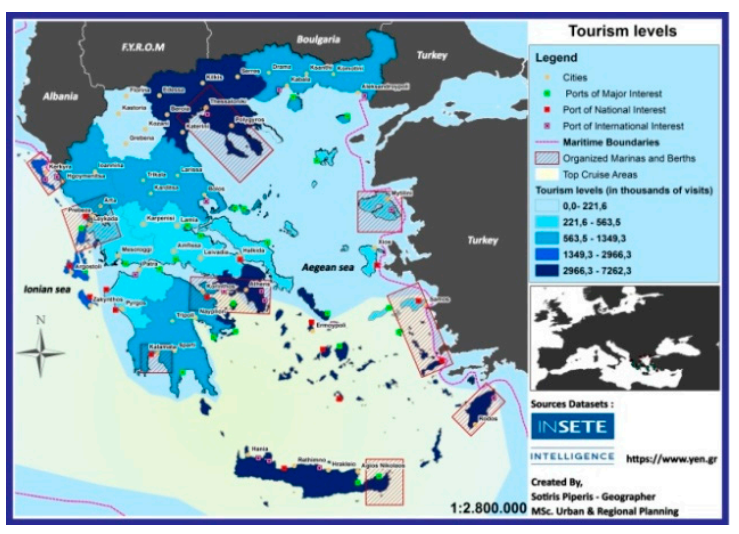

(b)

Figure 7. Aegean Sea-GIS mapping of: (a) Global shipping connections; and (b) main touristic areas [31].

With the existence of a multitude of islands, the border areas of the Aegean Sea are of particular interest, with the small frontier islands constituting a vulnerable category [20,22,23] (e.g., Psara, Oenousses, Thymaina, Agios Efstratios, Fournoi, Patmos, Leros, Nisyros, Symi, Chalke, Castelorizo and others). This category, due to scale, intensity of spatial issues and developmental prospects can function as a fertile field of experimentation [21]. These are places transitioning from traditional to modern forms of development, but which still have margins to avoid the trends to alter their local features. This is why they could be utilised as a research field to seek out alternative developmental planning options/practices to restart local societies and administer their resources on the one hand, but also as a research field to evaluate the effectiveness of the existing administrative structure, the relationships between centre and periphery and the degree local administrations have power for autonomous actions. All these under conditions that impose development and the support of actions and initiatives for collaborations between states to deal with issues of local, trans-regional, trans-national scale, such as: Environmental pollution, climate change, energy policy, security, flows of migrants and refugees, trade, tourism.

Along those lines of investigation, the ongoing research in the Aegean Sea (Section 2.2) seeks to make a contribution to a pilot reference field of vulnerable frontier segments, where there are many small islands with history. Evaluating of their particular features and their comparative advantages as 
well as the relationships of dependency and collaboration ${ }^{8}$ between them supports the claim that their development can be achieved by managing their local human resources and their natural and cultural heritage in a logical organisation of "networks of knowledge and culture" of supralocal/supranational reach. A goal, which in order to become action, requires the existence of an insular policy that is integrally correlated with the attempted spatial planning (territorial, maritime).

Unfortunately for Greece-a coastal and insular country with a naval history-despite the efforts made on the level of scientific research and political intentions (Section 2), there has never to date been an integrated effort to deal with the insular space. The ongoing research in the Aegean Sea has been functioned as fruitful ground to re-exam "open" issues which have to become part of the Greek insular policy. Towards that direction, at this stage of investigation, the certain research underlines the importance of: (i) Highlighting the necessity of preserving and disseminating local traditions and know how as a means of modernization and restarting local economies and as a mechanism of island recover $[5,13,15,16,19,23,28,29]$, (ii) marking out the power of dialogue and confirmed that many difficulties could be overcome when we work on common goals within a spirit of friendship and cooperation $[4,7,20,21,32]$, (iii) confirming that we are moving towards new "developmental paths" which underline not only the importance of establishing creative crossboarder cooperation among island and island regions but also its preservation in time $[4,5,8,11,13,27]$, (iv) recalling the "deficit" namely the lack of an "island policy", part of which should be a "management strategy" of cultural heritage and human resources $[2,3,6,10,12,22,24,25]$.

Starting with the above issues that arose from the specific research in the Aegean and author's broader scientific activity [14,15], in the last section opinions are expressed in the framework of principles and directions that should govern the formulation of s Greek insular development policy, recognising the significance of: (i) Clarifying the basic concepts of spatial planning (e.g., smart development, networking, local need, participatory processes); (ii) jointly evaluating and correlating the developmental and planning choices and the hierarchy of priorities for the islands and island regions, in order to create a common denominator on the level of analysis and application (Section 7).

\section{The Need for the Existence of a Greek Insular Development Policy-Challenges and Dilemmas}

The absence of an overall insular development policy from the planning system of Greece-a country with the 10th largest coastline worldwide, on which the majority of its settlements/cities can be found and a multitude of islands that covers $19 \%$ of its territory—could be considered to be inconceivable (Section 2). Despite this, it is almost expected under conditions where there is a clearly ascertained ineffectuality of planning in action, which fails to function fairly through democratic procedures. Unfortunately, despite the progress seen on a level of theoretical models, planningin Greece in practice continues to be designated through technocratic procedures and to be attempted in a fragmentary manner (or not at all) at various spatial levels of planning and administration, without strategy, irrespective of its links to the developmental model and the real local needs of its population [2,11]. At the same time, on a European level doesn't seem to exist a stable formulated position regarding the development of insular space on a theoretical and /or practical framework with policies for "endogenous development" not having been specified on a level of application for the particular problems of each individual area $[4,9,12,32]$.

However, even where no unanimity exists on either a European or a national level regarding planning for setting up insular development policies the context of the present conditions and trends following the appearance and spread of the crisis, imposes a different way of dealing with local and regional issues in central (developed) insular areas and less central, by co-evaluating special

8 Recording, classifying, evaluating focusing on structures for education, culture, tradition - in correlation with the natural and manmade environment, the administration and the local society (e.g., professional bodies, unions and associations, local organisations and citizens' initiatives). Emphasis is given on local/(trans) regional and supralocal networks of collaboration. 
parameters (Sections 2 and 4). As in the case of Greece where, almost all the insular regions (except for Crete) constitute insular complexes (archipelagos) including very many small islands, such regions have not really been recipients of the development efforts due to their satellite relationship with larger islands and/or mainland areas [2]. This results to their developmental downturn and gradual abandonment. Under these circumstances, significant scientific efforts are being made to re-boost local societies [13-15,20,21,23,28,29]. The problem is they work independently and not as a part of a comprehensive island policy. The reason is that there is no such developmental policy for Greek islands and island regions. It is more than a decade now, when alongside the General Plan for Spatial Planning and Sustainable Development (2008), a Special Plan for coastal and mountain space formulated in Greece without being instituted [2]. Unfortunately, since then nothing has changed (Sections 2, 5 and 6). It is obvious that, there is still much work to be done at the administration level, where the decisions are taken (Supplementary Materials).

Following the failure of the centre to fortify peripheral areas (after the seventies, a condition that continues to be in effect), the trend on a European level is to correlate socio-economic, environmental, cultural worries in forming an insular development policy with the strategic choice to integrate islands into broader political/social/economic networks, through which they will define their own particular role in a supralocal spatial/functional system, maintaining in parallel their own identity with a sole exchange of losing whatever autonomy they have and whatever benefits they derive from their isolation. Such a transition requires redefining a methodological framework for dealing with spatial phenomena, including urban concentration and sprawl, new relationship of city/countryside, spatial networking and strengthening of the role of medium and smaller sized cities, intelligent creative spaces, resilience, administration of resources, etc., and designating new criteria to evaluate the consequences thereof. Actions which are necessary in order to construct a flexible, expressly formulated insular development policy that is grounded on spherical logic and is capable of maintaining the main balances in the economic, social, and environmental sectors; be controlled by local forces; making use of the local dynamics; and accepting cultural, societal and technological variety $[2,6,11,32]$ (Figure 8 ).

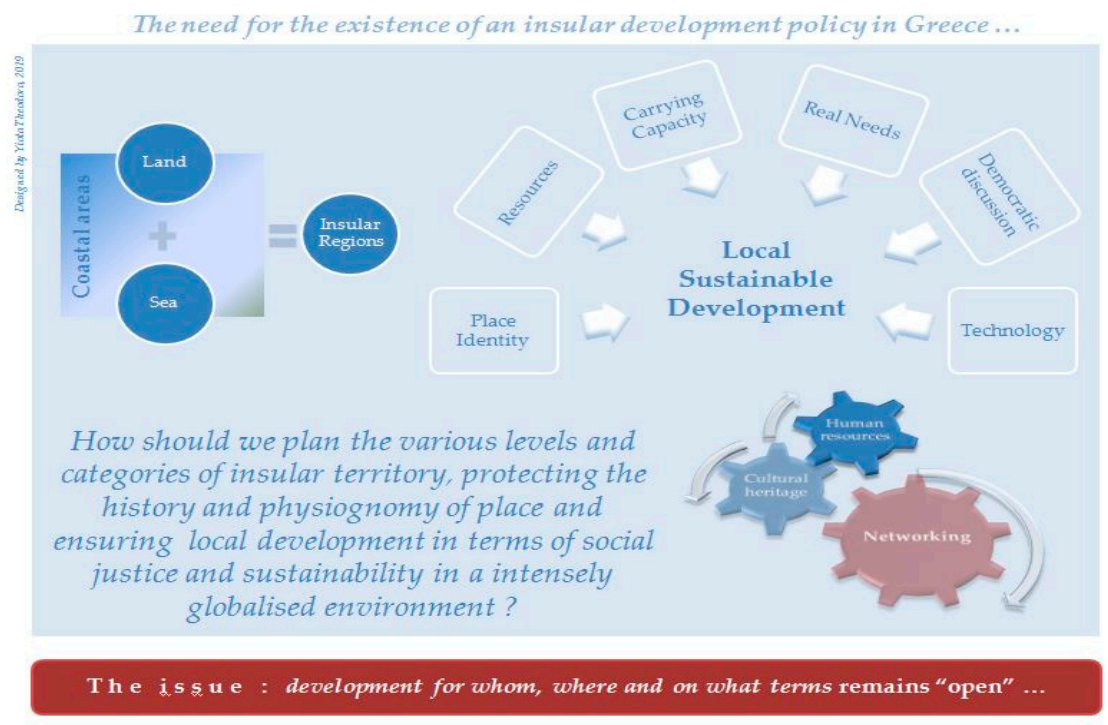

Figure 8. Towards an insular policy in Greece-issues for local development (designed by Yiota Theodora, 2019).

On the prospect of the evolution of a network society, linking places and people, and being characterised by economic integration, political coordination, regional economy and population mobility, Greek islands can play a major role as development agents in the SE Mediterranean [13-15]. In order for this to take place, however, Greek islands must simultaneously be dealt with as a part of a broader space (national and supranational) on the basis of a multidimensional dynamic approach 
mainly on matters of access, networking, distance, reach of local markets, comparative advantages, local culture and developmental dynamics (Sections 2 and 4). This requires the formulation of an integrated insular policy, whose basic principles shall be: (i) Protecting the natural and cultural heritage [5,23,28,29]; (ii) planning infrastructures and activities in line with the carrying capacity of places as well as their resources, natural ecosystems and local identity [13-15,30]; (iii) providing education to the population in order to raise awareness and cultivate a sense of joint responsibility [4,20,21]; (iv) selecting the most relevant spatial level (i.e., island/insular unit) for planning and implementing planning interventions [2,10].

Within the framework of the above principles, a crucial role shall be undertaken, amongst many other issues, by:

- Evaluating the dynamics of the insular urban network on a (trans)regional and transnational scale and the inviolable links with the mainland portion of the country and the neighbouring countries [2,11];

- Focusing on the dynamic areas of insular space, but also on those which can assist in wealth creation and employment by utilising knowledge produced elsewhere in managing and evaluating their comparative advantages [13,23];

- Redefining the relationship between city/countryside as well as marine/submarine/coastal space/mainland interior in order to have the best possible use of the natural/cultural heritage and tradition [4,5];

- Protectingand promoting the authenticity of placesand landscapes/seascapes and managing them within the framework of super-national discussion [14,15];

- Approaching issues of resilience and harmonious coexistence of history/tradition, tourism development, etc. [28,29];

- Supporting education, training and skills' improvement of local population for steering new job opportunities and promoting innovation and the use of new technologies [4,23];

- Making the best use of new structures for participatory governance, while also supporting administrative decentralisation $[20,21]$.

In order to support the extroversion of island areas and their internal cohesion, the rationale of parallel actions by independent spatial policies must stop and must be replaced by a framework, setting up coherent and mutually-reinforcing policies that restructure hierarchies of insular urban network, highlight foci on natural and cultural heritage, support local human resources, reinforce production infrastructure/techniques and strengthen employment opportunities(rural and tourism development, energy policy, transport policy, and others). Digital technology can be a lever and the main mechanism for conducting spatial analysis and support the decision-making processes [13-16,21,28,29]. The contribution of the academic/scientific world would be catalytic in this effort, through its educational, research, social role, which must be focused on raising awareness that that space must concern and simultaneously be designed on spatial levels of action in relation to mechanisms, ways and procedures for protection, management and regulation, through gaining skills such as critical thinking, communication and inter-scientific collaboration [4] (Supplementary Materials). Such a contribution is essential, since spatial planning constitutes a process of political significance due to the multiple influences on places and local societies.

Supplementary Materials: The starting point for the ongoing research in the Aegean was a book under the title: Maritime Space _ Urban Coastal Front__Port Cities, edited by Yiota Theodora, Associate Professor NTUA. The book is available at www.arch.ntua.gr/publication/14430 (Figure 2).

Funding: This research received no external funding.

Acknowledgments: Author acknowledges the creative support of all those people from the Greek islands' local administrations and communities, and from the School of Architecture of the National Technical University of Athens (N.T.U.A.) and highlights their sensitivity and awareness on issues regarding spatial development and planning. Special thanks go to Sotiris Piperis, who has closely cooperated in mapping the Aegean Sea. 
Conflicts of Interest: Author declares no conflict of interest.

\section{References and Notes}

1. Schönwandt, W. Planning in Crisis? Theoretical Orientations for Architecture and Planning; Ashgate: Aldershot, UK, 2008; pp. 3-46, 51-53.

2. Theodora, Y.; Loukakis, P. Regional Frameworks for Spatial Planning \& Sustainable Development. Institutional Regulations \& Prospects for Implementation. In Urban \& Regional Developments, Greece 1952-2012: Experiences in Practice; University Publications of Thessaly: Volos, Greece, 2018; pp. 303-312, ISBN 978-960-9439-44-2.

3. Nagy, G. Knowledge-Based Development: Opportunities for medium-Sized Cities in Hungary. Eur. Urban Reg. Stud. 2001, 8, 329-339. [CrossRef]

4. Theodora, Y. The issue of teaching "Spatial Planning"-Thoughts on dealing with modern requirements and challenges of development of space. In Maritime Space-Urban Coastal Front-Port Cities, a Collection of Texts on Spatial Planning; Theodora, Y., Ed.; National Technical University of Athens (N.T.U.A.), School of Architecture, Urban Planning Research Lab: Athens, Greece, 2018; ISBN 978-618-80734-6-3. Available online: http://www.arch.ntua.gr/publication/14430 (accessed on 10 April 2019).

5. Theodora, Y. Creativity and Historical City Centres; Attempting Urban Development through Supporting Tradition and the Arts Professions; 6th Inter-University Seminar on Sustainable Development, Culture and Tradition, on the topic of: Highlighting the Character of the place, Syros Institute: Syros Greece, 2016; pp. 54-63, ISBN 978-618-81312-2-4.

6. Theodora, $\Upsilon$. Knowledge as a Parameter in the Theories of Spatial Development; Scientific Volume in honor of Professor Emeritus P. Loukakis: Gutenberg, Greece, 2009; pp. 241-285. ISBN 978-960-87470-1-2.

7. Van Winden, W.; van den Berg, L. Cities in the Knowledge Economy: New Governance Challenges; Euricur: Rotterdam, The Netherlands, 2004.

8. Batten, D. Network cities: Creative urban configurations for the 21st century. Urban Stud. 1995, 32, 313-327. [CrossRef]

9. Hall, P. Urban and Regional Planning, 4th ed.; Routledge: New York, NY, USA, 2002; pp. 147-187.

10. Theodora, Y. Land Uses as an Expression of the Developmental Model in Space. Issues of Methodological Consideration for Spatial Development and Regulation; A collection of Papers; National Technical University of Athens-School of Architecture, Department of Urban \& Planning: Athens, Greece, 2014. Available online: http://www.arch. ntua.gr/node-resources/1181\#2180 (accessed on 10 April 2019).

11. Theodora, Y.; Loukakis, P. Typology of Greek Cities on Spatial Criteria of Regional Gravity. In Aeihoros; University of Thessaly: Volos, Greece, 2007; Volume 7, pp. 128-157. Available online: www.aeihoros.gr/ issues/el/issue/aeixoros-4-2 (accessed on 10 April 2019). (In Greek)

12. Atkinson, R. An Urban Policy for Europe; University of Portsmouth, School of Social \& Historical Studies North: Portsmouth, UK, 1999.

13. Networks: "Isolario"-The Cultural Project is a Series of Actions Designed for the Small Islands of Cyclades. 2019. Available online: http://www.mediadellarte.gr/greek/nisologio_gr.html (accessed on 21 May 2019).

14. Avgerinou-Kolonia, S.; Beriatos, E. (scientific coordinators) Supporting Maritime Spatial Planning in the Eastern Mediterranean-SUPREME; N.T.U.A. — School of Architecture/UTH—PRD: Athens, Greece, 2018. A Multi-beneficiary Research Action funded by the European Commission-EASME.

15. Avgerinou-Kolonia, S. (scientific coordinator) Mediterranean Cultural Network to Promote Creativity in the Arts, Crafts and Design for Communities' Regeneration in Historical Cities [MEDNETA]; N.T.U.A.-School of Architecture: Athens, Greece. 2014-2015 A Project funded by the European Union, ENPI—CBCMED [Cross-Bordered Cooperation in the Mediterranean], Available online: www.medneta.eu (accessed on 21 May 2017).

16. Theodora, Y. Place-Culture-Technology; Prospects in Spatial Planning for the 8th Inter-University Seminar on Sustainable Development, Culture and Tradition, on the topic of: Culture and Digital Technology, Syros Institute: Syros Greece, 2016; pp. 101-126, ISBN 978-618-81312-4-8. Available online syrosinstitute.eu (publications) (accessed on 10 April 2019). 
17. Avgerinou-Kolonias, S.; Theodora, Y.; Regeneration Planning of Arts Crafts \& Design (ACDs). Results of SWOT Seminar in Athens. In Proceedings of the 1st MEDNETA Conference on Creative Industries \& Urban Regeneration, ENPI CBCMED-Mediterranean Cultural Network to Promote Creativity in the Arts, Crafts and Design for Communities' Regeneration in Historical cities, Tunis, Tunisia, 15 December 2014; pp. 30-45, ISBN 9789938142679.

18. CIVVIH-ICOMOS, International Day of Monuments. Preservation development and monitoring of historic cities in 21st century. In Proceedings of the Conference and Annual Assembly of the International Scientific Committee of Historic Cities \& Villages, Corfu, Greece, 18-20 April 2002.

19. Theodora, Y. Strategies for ACDs' revitalization as a means for communities' regeneration in MEDNETA historical cities: An Introduction, in 1st Panel Specific Strategies for revitalization of Arts, Crafts \& Design (ACDs) in each MEDNETA city, ENPI CBCMED Cross Border Cooperation in the Mediterranean-MEDNETA, Mediterranean cultural network to promote creativity in the arts, crafts and design for communities' regeneration in historical cities. In Proceedings of the 2nd MEDNETA Conference on Cross Border Cultural Dialogue to Return Creativity in the Mediterranean Historical Centers: Strategies \& Tools, Athens, Greece, 14 December 2015; pp. 25-27, ISBN 978-618-80734-5-6.

20. Panagou, N.; Kokkali, A.; Stratigea, A. Towards an integrated participatory marine/coastal and territorial spatial planning approach at the local level-planning tools and issues raised. Reg. Sci. Inq. 2018, 10, 87-111.

21. "Gavdos Communities", Participator Planning for Sustainable Development, Management Organisation Unit of Development Programmes, Ministry of Economy and Development. 2019. Available online: https: //www.mou.gr/el/Pages and https://www.facebook.com/gavdoscommunities/ (accessed on 21 May 2019).

22. Theodora, Y. Case Study 5: Myrtoon Sea-Greece. In Proceedings of the SUPREME Project: Supporting Maritime Spatial Planning in the Eastern Mediterranean, Athens, Greece, 23-24 November 2017.

23. Theodora, Y. GeoSites-Human Places, Educational \& Research Workshop: Young Planner Researchers Study Greece, Organised and Coordinated by Theodora, Y., Associate Professor NTUA. Presented on the Researcher's Night 2017 at the NTUA. 2017. Available online: http://www.arsakeio.gr/gr/infrastructure/natural-historymuseum/educational-activities/33760-gewtopoi-topoi-anthrwpwn (accessed on 21 May 2019).

24. Florida, R. The Rise of the Creative Class; NY Basic Books: New York, NY, USA, 2014.

25. Florida, R. Cities and the Creative Class; Routledge: Abingdon, UK, 2005.

26. Couch, C.; Fraser, C.; Percy, S. Urban Regeneration in Europe; Blackwell Science Ltd.: Oxford, UK, 2003 ; p. 2.

27. Theodora, $\checkmark$. Approach to the effects of Greek regional universities on development of the country regions. In Regional Analysis and Policy. The Greek Experience; Coccossis, H., Psycharis, Y., Eds.; Springer: Berlin, Germany, 2008; pp. 249-270, ISBN 978-3-7908-2085-0.

28. Koutsi, D.; Stratigea, A. Unburying hidden land and maritime cultural potential of small islands in the Mediterranean for tracking heritage-led local development paths. Heritage 2019, 2, 62. [CrossRef]

29. Argyropoulos, V.; Stratigea, A. Sustainable Management of Underwater Cultural Heritage: The Route from Discovery to Engagement-Open Issues in the Mediterranean. Heritage 2019, 2, 98. [CrossRef]

30. Piperis, S. Greek Maritime Space-A Geographic Approach of its Dynamics with an Emphasis on Energy Sector. Master's Thesis, NTUA, School of Architecture, Athens, Greece, 2017. Postgraduate Programme: Urban and Regional Planning, Supervisor: Yiota Theodora, Associate Professor NTUA.

31. Piperis, S. Maps' Sources: (Figure 6a) Natura 2000 Network 2019. Available online: http://www.eea.europe.eu; (Figure 6b) Archaeological and Monumental Sites: http://listedmonuments.culture.gr; http://bluefrag.global; http://geodata.gov.gr; (Figure 7a) Global Shipping Connections http://www.geodata.gov.gr; http://storymaps. arcgis.com; http://diva-gis.org; and (7b) Main Touristic Areas: http://yen.gr (accessed on 1 March 2019).

32. Camhis, M. European Union and Cities: The urban dimension of Community policies. In Proceedings of the Conference: The Policy of Sustainable Urban Development in Greece; Jointly Organized by the Faculty of Architecture of the National Technical University of Athens and the Ministry of the Environment, Spatial Planning and Public Works: Athens, Greece, 2005; pp. 17-23.

(C) 2019 by the author. Licensee MDPI, Basel, Switzerland. This article is an open access article distributed under the terms and conditions of the Creative Commons Attribution (CC BY) license (http://creativecommons.org/licenses/by/4.0/). 